\title{
Michel Foucault en die historisering \\ van Anderswees
}

\section{Johann Beukes \\ Kriel}

\begin{abstract}
Michel Foucault and the historization of Otherness

In this article the intimate relation between power, history and historiography is explored within the context of the postmodern philosophy/ historiography of Michel Foucault. Foucault confronts us with a timeless question: do we recognize our own dicourses of power? Do we recognize the Other, the victims of instrumental reason?
\end{abstract}

At the end of the Middle Ages leprosy disappeared from the face of the earth.

(Michel Foucault: Opening sentence in Madness and Civilization)

\section{INLEIDING}

Hierdie artikel wil poog om via die postmoderne filosofie van Michel Foucault 'n invalshoek aan die orde te stel om 'n bepaalde nuanse in die moderniteitsdebat te verhelder: dit behels die postmoderne filosofie se tegemoetkoming of bereddering van die verdronge aspekte van die moderne werklikheid wat in navolging van Derrida die Ander (l'Autrui) genoem kan word (kyk bv Derrida se gesprek met Levinas [1978: $102 \mathrm{ev}])$. Die uitgangspunt hier is dat die historiografiese filosofie van Michel Foucault 'n argumentatiewe platform verskaf vanwaar algemene postmoderne kwessies verken kan word, en dat 'n mosaiek van postmoderne perspektiewe in daardie onkonvensionele historiografiese werksaamhede van Foucault teruggevind kan word.

Hierdie vertrekpunt word argumentatief soos volg ingerig:

* Inleidend en agtergrondsgewys word aangedui waarom Foucault dit teen moderniteit en spesifiek moderne geskiedskrywing het. Dit gaan naamlik veral oor die perspektiefverengende nawerking van die moderne instrumentele rede, wat deur Foucault historiografies geproblematiseer en uitgedaag word.

* Hierdie artikel is gebaseer op navorsingsresultate verkry in tie D Litt et Phil-proefskrif van C J Beukes, 'Nietzsche in Adorno: Oorspronge van postmoderniteit?', Departement Filosofie, Randse Afrikaanse Universiteit 1995, onder leiding van prof dr I J Snyman. Publikasievergunning en finansiële bystand deur RAU en die SWO (RGN) word hiermee met dank erken. 
* Voorts word 'n wesenskenmerk van die postmoderne filosofie beskryf, naamlik dat postmoderniteit wil poog om met die bevordering van 'n pluraliteitsbenadering tot die werklikheid die verengende nawerking van die moderne rede te demonstreer, om vanuit hierdie demonstrasie 'n verset teen moderniteit van stapel te stuur. Postmoderniteit word daarom hier Foucauldiaans geskakeer as sou dit te doen hê met ' $n$-historiserende diagnose van moderniteit en die daarstelling van ' $n$ kritiese prognose in postmoderniteit. Daarmee word bedoel dat Foucault moderniteit se oorspronge krities-diagnoserend aanspreek en 'n postmoderne kritiek van die subjek op hierdie diagnoses bou. Opvolgend word daar aan die hand van Foucault se postmoderne filosofie aangetoon wat die aansprake van postmoderniteit is en behoort te wees, en word die problematiese kwessie van produktiewe (eie) mag in Foucault se filosofie krities teen homself uitgespeel.

\section{MODERNITEIT: FOUCAULT SE DIAGNOSE}

Foucault se kontra-moderne en meer spesifiek kontra-historiese stellingname het te make met die feit dat moderniteit se eie magsdiskoerse hom tot by 'n selektiewe verdaging van sekere momente uit die geskiedenis gebring het. Met 'kontra-histories' word bedoel dat Foucault in die ongelyk kom met die moderne subjek se voorstelling van die historiese werklikheid en die historiese verstaan van die Self: Foucault het dit daarom teen beide die moderne geskiedenis en moderne geskiedskrywing. Foucault problematiseer historiese moderniteit dus omdat moderniteit deur 'n selektief-historiografiese verstaan van homself ' $n$ uiters bedenklike tradisie teweeggebring het.

Foucault het egter geen verlossende pretensie en geen pretensie om die moderne rede te genees nie. Foucault problematiseer en agiteer deur te demonstreer. Sy vertrekpunt is dat waar met die sogenaamde selfgenoegsame moderne rede in die gerig getree word, demonstrasie genoegsaam is. Foucauldiaans, of epogdemonstratief/agiterend dan, sou inleidend gevra kon word: Waar het moderniteit se verdaging van segmente van die werklikheid begin?

Daar sou aangevoer kon word dat moderniteit se selektiewe verdaging van segmente van die werklikheid minstens formeel en epoggewys by Descartes se teenoorplasing van subjek en objek begin het. Die pretensie van hierdie teenoorplasing was dat die subjek se selfgenoegsame redelikheid hom in staat sou stel om die werklikheid ook die historiese werklikheid - volledig en finaal te ken. Die res cogitans - die kennende subjek - word teenoor die res extensa - die objek wat geken word - geplaas. In hierdie dualisme en teenoorplasing maak die kennende subjek aanspraak op volledigheid. Die probleem is egter, en dit blyk postmodern-retrospektief al duide- 
liker, dat die kennende handeling nié volledig is nie: daar was verdronge en verdaagde segmente waarmee moderniteit nie in die reine probeer kom het nie. Daar was iets wat buite hierdie epistemologiese sisteem en teoretiese redelikheid gestaan het: dit wat nie geken kan word nie, dit wat nie teoreties geartikuleer kan word nie, ervarings wat die denke se identifiserende handeling telkens ontsnap, ervarings wat moeilik indien enigsins gedokumenteer kan word. Die moderne tradisie sou leer dat die sterkste pleegkind van hierdie tradisie, die instrumentele rede, onbegrens is.

Die rede het in die rasionalistiese tradisie 'n sisteemaangeleentheid geword wat gepretendeer het dat niks - ook niks histories - buite die teoretiese draagwydte daarvan kon bestaan nie. Vir figure soos Foucault blyk dit egter retrospektief al hoe waarskynliker dat daar baie dinge buite hierdie teoretiese redelikheid gestaan het, dinge wat stelselmatig deur die bloudrukaard van die teoretiese rede verdring en verdaag is. Die gevolg van die werksaamhede van die rasionaliste, en daarna ook Kant en Hegel, was dat die rede gepretendeer het om die geheel te ken en niks uit te sluit nie, maar dit desnieteenstaande wel doen. Die instrumentele rede het geweier om te kapituleer voor die dwang om erkenning te gee aan die dinge wat nie in die bloudruk van die moderne tradisie pas nie. Die moderne rede is behep met presisie en metode, en verdring alles wat nie so presies en metodies gedokumenteer kan word nie. Foucault egter, het hierdie presisie met 'n selfs groter historiese 'presisie' ondermyn.

Die moderne rede, en daarom ook die historiserende funksies van die rede, wat 'n mens ook vergeskiedeliking kan noem, het volgens Foucault immer uitgesluit en selektief ingesluit, veral met betrekking tot die neiging om die dinge wat nie in die kraam van die moderne rede sou pas nie, in die ongelyk te stel as nietig of irrelevant. Die Westerse rede was van meet af aan diskriminerend: die rede het gediskrimineer teen die veranderlike, die eindige, die toevallige, die partikuliere, die affektiewe en veral die irrasionele en a-rasionele. Die Westerse rede het in die proses die blywende, die oneindige, die noodwendige, die universele, die argumentatiewe en die onbetwyfelbare begunstig. Hierdie instrumentele omgang met die werklikheid het ook in die moderne geskiedskrywing neerslag gevind.

Die postmoderne filosofie egter, en dit geld veral vir Foucault, het begin om die moderne rede en sy funksies juis te definieer in terme van die uitsluitings wat hy maak: wat vir 'n filosofie of epog as redelik gegeld het, word volgens denkers soos Foucault omgekeerd duidelik wanneer aangetoon kan word wat vir hom as onredelik, ontoelaatbaar en verdronge - as Anders - gegeld het. Foucault het daarom in sy werk baie moeite gedoen om hierdie verdringingsprosedures te identifiseer wat werksaam sou wees in die Westerse filosofiese diskoers vanaf die Grieke tot by die moderne filosowe, 
en het hierdie meganismes van uitbanning, verbanning en verdringing doelgerig aangespreek. Foucault se mees basiese argumentatiewe premisse was dat die moderne rede homself handhaaf deur verdringing en uitsluiting.

Ook ander postmoderne filosofieè, veral dié van Nietzsche, Heidegger, Derrida, Deleuze en Levinas wil die basiese probleem van pre-moderniteit en moderniteit diagnoseer as dat die rede in die Westerse tradisie altyd 'n eksklusiewe rede was. Foucault se kritiese agenda word daarom grotendeels beslaan deur die vermoede dat die ware aard van die rede dáár lề waar dit nié verdring nie, en die poging om aan die bewussynsfilosofiese paradigma as die spitspunt van hierdie verdringende werksaamheid, te ontkom. Vir Foucault tree die rede se ware aard na vore daar waar dit slaag om nié uit sluit nie, maar die Ander - die histories gekleineerde - segmente van die werklikheid te herken, te erken en in te sluit. Ware redelikheid sou vir die postmoderne filosofie dus ' $n$ redelikheid wees wat bereid is om met die Ander in die reine te kom: nie daar waar redelikheid die grense sluit en dele van die werklikheid verdring en uitban nie, maar daar waar dit die grense postmodern oopbuig en Ander werklikhede inlaat, en aan dit wat in die moderne bewussynsfilosofiese paradigma formeel nietig verklaar is, die nodige erkenning verleen.

Postmoderniteit, en dit geld eksplisiet vir die filosofie van Foucault, wil in haar prognose die verdronge Ander tegemoet kom deur rekening te hou met die pluraliteit van dinge. Dit wil, anders gesê, nie dieselfde fout as moderniteit maak, naamlik om slegs enkele dele van die werklikheid te (h)erken en op te teken nie, en wil eerder rekening hou met die grootste moontlike hoeveelheid van dinge. Moderniteit so verdringing en selektiewe verdaging van bepaalde werklikhede het 'n bepaalde gefragmenteerdheid van die bestaan, van die Self, tot gevolg gehad. Postmoderniteit wil hierdie atome van die moderne werklikheid remediërend byeenbring en afskeid neem van die drie moderne meta-narratiewe wat hierdie fragmentering gedring het soos deur Lyotard (1984) getipeer (kyk hieronder).

Die probleem rondom die moderne rasionaliteitsideaal van 'n geheel of eenheid van kennis het juis ontstaan by die moderne pretensie van 'n eenheid van kennis wat bloot 'n pretensie gebly het, nooit 'n eenheid kon bewerk nie en wat in der waarheid tot verskillende vorme van rasionaliteit aanleiding gegee het. Volgens Lyotard was die drie meta-narratiewe wat hierdie pretensie van eenheid ten spyte van die verskillende rasionaliteitsvorme in stand gehou het die Verligting met al sy emansiperende potensiaal, die Idealisme met sy klem op die Wording en uiteindelik die teleologie van die (Hegeliaanse) Gees, en ook die hermeneutiek van die Historisme. Toe die gemeenskaplike aan hierdie drie meta- of meesternarratiewe, naamlik die pretensie om die geheel van dinge te verteenwoordig, in gedrang begin kom het omdat die geskiedenis self hulle aansprake begin bevraagteken het, het kennis self in gedrang begin kom. 
Dit is die agtergrond van die moderne rasionaliteitskrisis. Foucault sien hierdie krisis in en wil iets daaraan doen. Foucault sien in dat geen enkele rasionaliteitsvorm op selfgenoegsaamheid en selfgeldendheid kan aanspraak maak nie.

Foucault beoog daarom eerder om hierdie verskillende rasionaliteitsvorme neweskikkend te stel, en nie onderskikkend op grond van die een of ander aanspraak op absolute geldigheid nie. Foucault se postmoderne rasionaliteitsbegrip, wat haar onkonvensionele geskiedenisse bepaal, wil daarom inderdaad met die pluraliteit van alle dinge rekening hou.

Onder hierdie pleidooi vir die plurale of meervoudige kan met ander woorde nie langer die likwidering van die partikuliere of enkelvoudige verstaan word, soos wat byvoorbeeld Hegel dit verstaan het nie. Hegel rig hom op die geheel ten koste van die partikulariteit van die dele van daardie geheel. Dit kom by Hegel neer op ' $n$ totaliserende geskiedsvisie of eenheidsnarratief. Die postmoderne filosofie wil aan hierdie histories-totalitêre eenheidsgedagte ontkom deur die verhouding tussen die partikulieres as sodanig - en nie ter wille van die een of ander geheel nie - te ondersoek en te erken. Foucault se 'geskiedenisse' is sprekend hiervan.

\section{MICHEL FOUCAULT AS KAMPVEGTER VIR HISTORIESE ANDERS- HEID}

Met bostaande as agtergrond, gaan ons nou oor tot 'n tipering van Foucauldiaanse geskiedskrywing - wat ook getipeer kan word as die dokumentering van die ervaring aan Anderswees - as 'n prominente verskyningsvorm van postmoderne kritiek. Dit sou bevorderlik vir 'n verstaan van hierdie aspek van Foucault se filosofie wees om die objek van sy kritiek - die historiese bronne van filosofiese moderniteit - nader te omskryf. Hiervoor kan die skerp insigte van Charles Taylor met vrug ingespan word. Die Foucaultresepsie wat hier aan die orde is, waar Foucault geskets word as 'n onkonvensionele blootlegger van die geskiedsfilosofiese agtergronde van die Westerse tradisie, word in Taylor se werk, Sources of the Self: The making of the modern identity (1989), gesaghebbend bevestig.

In sy werk poog Taylor, parallel met die soort werkwyse wat ons by Foucault aantref, om tot ' $n$ historiese verstaan van die oorspronge van die moderne identiteit of Self te kom. In hierdie poging om die grondslae van die moderne identiteit te peil, doen Taylor - soos Foucault - moeite om vas te stel wat in moderniteit nié as identiteit gegeld het nie, met ander woorde, wat Anders as die Self is en buite die ruimte van 'n selekterende en verengende redelikheid lê. Taylor verwys na 'the voice of nature' (Taylor 1989:305) en 'inwardness' (Taylor 1989:111), om aan te toon dat die 'inner- 
like' en die 'natuurlike' aan ons identiteit grootliks deur die instrumenteel-redelike moderniteit verbygegaan is. Weliswaar word Taylor (1989:25) se argument deur morele oortuigings en motiewe bepaal, maar juis binne die postmoderne argumentasie vir vervloeiing verwys hy na sake wat buite die sfeer van die destyds-eensydige morele gesprek lê waarvan die belangrikste die 'onartikuleerbare' (Taylor 1989:53) is. Onder 'innerlike' en 'natuurlike' verstaan Taylor sake soos die instinktiewe en toevallige, wat deur die identifiserende sisteemdenke in sy verenging van redelikheid agtergelaat en uitgeban is: hierdie is sake wat volgens Taylor al in só ' $n$ mate verdring is dat daar eintlik nie meer daaroor gepraat kan word nie, dit is onartikuleerbaar.

'n Gevolg van hierdie (h)erkenning van dít wat onartikuleerbaar is, kan in die strategie om die Self of identiteit behoue te laat bly, afgelees word: om 'goed' te doen aan die Ander is om 'goed' te doen aan die Self. Om 'n Ander tegemoet te kom is nie 'n kulturele reaksie nie, maar is veronderstel om 'n natuurlike, instinktiewe reaksie te wees. Taylor se argument wentel grootliks rondom die probleem waarom dit juis nié in moderniteit gebeur het nie, maar die moderne identiteit 'n nie-identiteit afgrensend tot stand gebring het, en die moderne Self die moderne Ander letterlik verpletter het. Taylor fokus in hierdie verband op Plato, Augustinus, Descartes en Locke as oorspronge van moderniteit, en hy poog om die Ander met 'n herlees van hierdie oorspronge van moderniteit tegemoet te kom.

Plato was volgens Taylor van besondere belang vir die moderniteit omdat die rede reeds by hom instrumentele en selfverwesentlike status verwerf, en - anders as by Plato se voorgangers - is die rede nie in die eerste plek 'kosmosordenend' nie, maar manipulerend (Taylor 1989:115). Volgens Plato is die mens moreel goed daar waar die rede heers, en hy/sy nie deur begeertes gerig word nie. Plato koppel orde en redelikheid aan mekaar: irrasionaliteit is buite die werksterrein van redelikheid. Hierdie standhoudende Platoniese erfenis sou volgens Taylor eers by Foucault inversief in perspektief gestel word. Ook Augustinùs is belangrik vir die moderniteit omdat die Self by hom verinnerlik word. By Augustinus is daar sprake van 'n wending na die Self (Taylor 1989:127). Hierdie verinnerliking lei tot die opvatting dat die wêreld $m y$ wêreld is. Omdat die wêreld $m y$ wêreld is, geskied alle ervarings en refleksies vanuit die eerste persoon: die werklikheid word Selfgesentreerd.

Descartes se poging tot 'n redelike Godsbewys deur 'n radikale Selftwyfel, wat uiteindelik in Selfverabsolutering opgaan (cogito ERGO sum), neem Augustinus se innerlikheidsbeskouing veel verder (Taylor 1989:143). Descartes verskuif naamlik die gedagte van Goedheid, in morele én ontologiese sin, vanaf God na die mens. Hy meganiseer Plato se redebeskouing, wat bloot die hedonistiese sug na die lyflike 
begeerte wou verhoed: die mens is die meganiese, vanselfsprekende bron van moraliteit, en nie meer God nie. Hierdie meganiese verabsolutering van die Self by Descartes lei tot 'n ontkoppeling van die wêreld en die Self: die wêreld, die extensa, word nou die dualistiese teenhanger van die Self, die cogitans. So word daar aan die moderne proses van disengagement en die fragmentering van rasionaliteit in verskillende vorme van rasionaliteit, ten spyte van sy eenheidspretensie, momentum gegee.

Locke poog om hierdie meganiese verabsolutering van die Self te legitimeer deur dit te objektiveer. Locke se 'punktuele Self' (Taylor 1989:159) verwerp die verinnerlikingsproses wat vanaf Augustinus na Descartes ontwikkel het, maar gaan in die proses met die internaliseringsproses verder: hy gee daaraan objektiewe gestalte deur die eerstepersoonervaring as voorwaarde vir kennis te beskryf.

Die punt wat Taylor wil maak is dat ons in hierdie vier eksponente van die moderne tradisie 'n proses van Selfinternalisering as oorsprong van moderniteit aan die werk sien. Daar was sedert Plato 'n stelselmatige keer na die Self, sonder om (ook moreel) ernstig aandag te gee aan dié dinge wat nie geïnternaliseer kan word nie: die Ander. Hierdie Ander is spesifiek deur die moderne optekening van die ervaring uitgesluit.

Die keer of wending na die Self waarna Taylor verwys - wat by Foucault en ook by die kritiese teorie baie skerp onder skoot gekom het - het 'n krisisbewussyn in die twintigste eeu tot gevolg gehad. Selfingenomendheid, wat 'n mens ook die verabsolutering van identiteit kan noem, het konkreet gesproke talle bose ideologieë tot gevolg geha, vernaamlik Fascisme en al die wisselvorme daarvan wat in hierdie eeu hooggebloei het. Voorts was daar in hierdie eeu twee wêreldoorloë wat nie net Europa verwoes en die Europese (veral Duitse) denktradisie in die ongelyk met homself gebring het nie, maar ook talle konflikte wat gespruit het uit die verabsclutering van identiteit. Auschwitz, byvoorbeeld, bevraagteken die korrektheid van die moderne optekening van die ervaring: 'n meer korrekte optekening van die moderne ervaring sou Auschwitz vooruitgesien/geantisipeer het.

Paradigmaties is die moderne aftakeling van sowel die kultuur as die natuur waarskynlik dít wat Nietzsche prospektief met sy (historiserende) uitspraak rondom die dood van God bedoel het. Foucault het daardie uitspraak baie ernstig geneem: die krisis van die twintigste eeu is inderdaad die krisis van nihilisme, die uiterste toestand van wanhoop, van beide fisiese en metafisiese verval. Die postmoderne filosofie, wat by uitstek by Heidegger begin en tot ontplooiing by Foucault kom, wil hierdie nihilisme erken en daarmee in die reine kom. Taylor sien by Foucault, as 'n filosoof by wie Nietzsche 'n baie diep nawerking gehad het, 'n filosofiese raamwerk raak wat die 
moderne identiteit se verabsolutering van die Self en die verdringing van die Ander teengespreek het (1989:93). Taylor sien in die werk van aanvanklik Nietzsche en daarnaas Foucault die begin van 'n bewussyn wat hierdie beskadiging remediërend kan aanspreek, deur met geskiedsbegrippe te werk waaraan tot dusver nie gedink is nie.

Foucault het 'n kritiese strategie ontwikkel wat Deleuze (1984:149) 'n 'kontrafilosofie' en 'kontra-geskiedenis' noem. Hierdie kontra-filosofie behels dat Foucault heterogeniteit of partikulariteit nie soos die moderne filosofie in terme van die struktuur en sisteem van subjeksentrisme benader nie, maar vanuit die histories-varieerbare aard van mag. Mag is vir Foucault nie iets wat deur subjekte besit en onderwerp kan word en instrumenteel-diensbaar gestel kan word (soos die rede) nie. Mag is eerder 'n allesdeurdringende netwerk van historiese verhoudings waaraan geen subjek kan ontkom nie: subjekte is beide die agente en produkte van mag. Die verskynings van magsnetwerke wat dikwels, byvoorbeeld in politieke stelsels, as iets negatief beskou word, is volgens Foucault misplaas - mag is nie iets wat 'bo' is en wat uitgeoefen word op diegene wat 'onder' is nie: mag is oral. Mag sirkuleer deur elke sel van die sosiale liggaam, dit is die mees basiese aspek van elke institusie, handeling en verhouding. Die optekening van ervaring moet in die eerste instansie die magsdiskoers wat vir die ervaring dikteer wat mág en wat nié mag nie, diagnoseer en opteken. Foucault is dus nie afwysend oor mag nie. Hy het dit eerder teen die moderne programme (of [historiese] 'tegnologieë', soos hy dit noem) van dissiplinering en onderwerping wat uit en uit met mag as medium werk, maar dit nie openlik erken nie. Mag is in moderniteit gekonfigureer tot iets wat as normaal en alledaags deurgaan, maar nie bekend staan of identifiseerbaar is as mag nie. Hierdie konfigurasie van mag in moderniteit wat die moderne Self by uitstek van die meganismes voorsien het waarmee die Ander histories stelselmatig en doelgerig onderwerp is, is die saak waarop Foucault hom rig.

Die begrip 'mag' word by Foucault uiteindelik volledig sentraal. Mag, in sy verwikkelde verstaan daarvan, is die medium wat Foucault sélf in staat stel om die strenge liniêre tydsverstaan opgesluit in moderne geskiedskrywing op te hef, en die geskiedenis sowél as die geskiedskrywing as magsdiskoerse aan te dui. Mag is ook die medium van die moderne geskiedsbeskouing/skrywing wat volgens Foucault veral te vind is in die pretensie van die moderne historiografie dat dit alles insluit en 'n makrobewussyn verteenwoordig. Foucault wil deur die moderne wetenskap, veral die psigiatrie en die onderskeie variante van geskiedskrywing, se fasade van objektiwiteit en algemeengeldigheid breek en die aandag daarop vestig dat hierdie aansprake maar net maskers is wat moderne onderwerpingstegnieke dra, en dat die sogenaamde 'normale' individu sowel ' $n$ produk as ' $n$ agent hiervan is.

Foucault sien mag dus tipies Nietzscheaans as 'n positiewe verskynsel. Mag produseer die werklikheid. Hierdie penetrerende insig in die aard en werking van mag is 'n dionisiese insig: dit noop 'n geskiedskrywing tot anti-formalisme en 'n anti- 
apolliniese stellingname. Dit beteken dat Foucault alle vorme van dissipline, historiese orde, (sogenaamde) normaliteit en uiteindelik die moderne individu self as die produkte van mag blootlê. Weer gesê: Foucault het dit nie teen die mag as sodanig nie, maar nogmaals teen die konfigurasie daarvan-in die histories-geïnstitusionaliseerde praktyke van moderniteit, byvoorbeeld die wat as (moderne) verskynsel onder die loep kom in sy belangwekkende eerste werk, Madness and Civilization: The history of madness in the age of reason (1965).

Foucault, blyk dit reeds in hierdie eerste werk, was dié kontrasubjektiewe kampvegter vir Andersheid. Hy het in sy 'historiese studies' en eiesoortige geskiedenisse nie oor gevangenisse geskryf nie, maar die gevangene. Hy het nie oor die institusie van gestigte geskryf nie, maar oor die waansinnige as slagoffer van die gestig. Hy het nie oor seks of pyn geskryf nie, maar oor die verband tussen seks en pyn. Hy was geïnteresseerd in die dood, nie in die lewe nie. Hy was geïnteresseerd in die liggaam, nie in die siel of veral Gees nie. Met ander woorde, Foucault bemoei hom met die dinge waarmee die moderne filosofie en moderne geskiedskrywing hom nie bemoei nie. Foucault was gemoeid met die Ander.

Reeds in hierdie eerste gepubliseerde werk (Madness and Civilization: The history of madness in the age of reason [1965]) is dit prominent. Dit is die goue draad in die Foucauldiaanse diskoers, reg deur sy oeuvre tot by sy beskrywing van die seksuele diskoers as magsdiskoers in History of sexuality. In Madness and Civilization is Foucault daarop uit om die betekenis of sin van waansin te rehabiliteer. Hy poog om 'histories' na te speur waarom en waar in die moderne geskiedenis begin is om waansin as 'n negatiewe verskynsel te interpreteer, en waarom die waansinnige ervaring vir die moderne denke op 'n siekte, 'n geen-ervaring, sou neerkom. 'Histories' - in aanhalingstekens - want Foucault se werk is geen geskiedskrywing in die gangbare sin van die woord nie: dit rig juis as 'n geskiedskrywing van die Ander 'n uitdaging aan die gangbare vorme van geskiedskrywing as skrywing(s) van die Self.

Foucault het dit in hierdie werk in elk geval nié oor die geskiedenis nie, maar oor die status quo, waar die rede se uitsluitende aard en selfgenoegsame pretensies baie duidelik begin blyk het. Uiteraard het hy met die werk die grondbeginsels van die moderne psigiatrie, wat met identifiserende beginsels of diagnoses werk, in twyfel getrek. Maar dit het vir Foucault ook daaroor gegaan om aan te toon dat die waansinnige toestand bloot ' $n$ Ander toestand is, en een wat nie minder werklik is as enige niewaansinnige toestand nie. Waansin word as Ander (h)erken en gerehabiliteer.

In History of sexuality doen hy dieselfde met die liggaam as wat hy in Madness and Civilization met waansin gedoen het: hy plaas die verwaarlosing en onderwaardering van die liggaam binne die Westerse-, en veral Joods-Christelike tradisie, krities in his- 
toriese perspektief en poog uiteindelik om aan te dui dat daar in die liggaam eweveel historiese werklikheid opgesluit the as in die gees of siel. Die liggaam as iets werkliks, maar Anders, word van die modemiteit se volgehoue pleitbesorging van die rede alleen gerehabiliteer. Dit behels egter nie 'n eenvoudige keuse teen die rasionele en vir die irrasionele nie. Foucault gaan baie ruimer te werk, want hierdie geskiedskrywing van die Ander word terselfdertyd Foucault se redekritiek.

Foucault baseer sy redekritiek, gedring deur die motief van die Ander, soms só op 'irrasionele' premisses, en lê sin en betekenis aan die hand van waansin bloot. 'Irrasioneel', in die sin dat hy van kritiese platforme gebruik maak wat vir moderniteit as kritiese gegewes taboe sou wees: onder meer die liggaam, seks, siekte en misdaad. Sy kritiek van die rede is dus geskiedskrywing, maar ook baie meer: 'n argeologie wat uitmond in "n soort (Nietzsche-geinspireerde) genealogie. Dit is inderdaad niks anders as 'n geskiedskrywing van die Ander nie, die dokumente van die Ander toestande van waansin en on-redelikheid. Vir Foucault is bloot die skrywing van die geskiedenis van persepsies en die behandeling van byvoorbeeld waansin juis reeds 'n refleksie op die illegitieme moderne konstitueringsproses van die redelike.

In die proses maak hy van die tragiese en die argaiese bedmaats: om waansin (die irrasionele) rasioneel te peil, is paradoksaal en moontlik réeds weer irrasioneel. Daarom wil hy die Westerse Self na Heidegger die finale nek slag toedien. Die Self moet anoniem word. Die Self moet nie net uit die sentrum van redelikheid verwyder word nie, maar verdaag word. Foucault sê self dat hy skryf 'om geen gesig te hê nie' (Foucault 1972:17). Foucault wou redekrities uit die subjekgesentreerde sirkel van die rede breek deur middel van die rehabilitering van die Ander. Foucault se redekritiek, anders gesê, is gesetel in en word tot uitdrukking gebring in sy eiesoortige historiografie van die Ander. Dit is inderdaad so dat Foucault baie gedoen het om die Ander as tipies postmoderne motief te vestig. 'n Mens sou baie wyd hierop kon uitbrei, met verwysing na onder andere Foucault se belangstellings in die berugte Franse tronkstelsel en sadomasochisme as die Anderkant van seks.

Hierdie Ander behels onder andere die gevangene, die waansinnige, die homoseksueel, die liggaam en die (groot) grys gebied tussen seks en pyn/oorheersing. Vir Foucault is die skryfproses, spesifiek die opskryf van historiese prosesse, daarop gerig om hierdie Ander te artikuleer, om dit tot spreke te bring. Die Foucauldiaanse skryfproses is daarom daarop gerig om die Self te laat vaar en die Ander te laat praat. Dit gaan vir Foucault daaroor dat die Ander deur die identifisering of diagnosering, kategorisering en sistematisering wat-die moderne skryfproses bepaal het, tot vergetelheid verdring is. Dit het in so 'n mate gebeur dat slegs 'n doelgerigte poging om byvoorbeeld waansin te herstel of te rehabiliteer, as korrektief op hierdie verdringing kan optree. Foucault se alternatiewe historiografie, of wat ook 'n geskiedskrywing van 
die Ander genoem kan word, is uiteindelik niks anders as die blootlegging van die verborge antagonismes waarmee mense as waansinning, krimineel en irrasioneel getipeer is nie. Die geslaagde rehabilitering van die Ander hang af van die geslaagdheid van die blootlegging van hierdie antagonismes. Daarom is Foucault se geskiedenisse niks anders as 'n kritiek van die moderne, verengende rede wat die Ander só antagoniseer nie. Die begrip van die ervaring van Anderswees staan daarom sentraal in Foucault se geskiedenisse. Foucault se geskiedenisse is uitein Jelik niks anders as die optekening van Ander ervaringe nie. Foucault wou poog om die ervaringe wat deur moderniteit as onwerklik of minstens minder werklik geag is, te boekstaaf as ervaringe wat ewe veel gewig dra, as gesistematiseerde ervaringe wat in kategoriee omskryf kan word.

Die moderne skrywing was gefikseerd op die bekende, kontroleerbare en kategoriseerbare ervaring. Die ervaring moet volgens die modernistiese paradigma geidentifiseer en gediagnoseer kan word. Foucault het dit as 'n ernstige leemte gesien: waar moderniteit hom so verlaat het op die kategorisering en identifisering van elke ervaring, wou Foucault die ervaring van die Ander oopskryf juis in die onkategoriseerbaarheid daarvan. Onder ervaring het Foucault iets verstaan wat histories begrond is (kyk Foucault 1985:6-7). Elke ervaring verwoord volgens Foucault 'n aspek van die bestaan en definieer 'n kennisveld. By elke ervaring moet daar geleer word, en die gedagte aan wat hy 'grenservaringe' genoem het, moet nagejaag word.

Grenservaringe is daardie gedifferensieerde ervaringe wat so op die randeindes van die bestaan lê, dat daar moeilik, indien enigsins, daaroor gepraat kan word (kyk Foucault 1965:ii). Foucault se strategie om van die ervaring in die skryf van sy geskiedenisse te vertrek, laat aan hom die ruimte om ook die Anderkant van die ervaring te verken, dít wat hy soms 'negatiewe ervarings' genoem het, oftewel ervarings wat rasionaliteit se kategorisering nie net ontkom nie, maar ontken. Nogtans, ten spyte van die oënskynlike onmoontlikheid daaraan verbonde, moet hierdie ervarings oordink word (Foucault 1965:ii). Die doel van sodanige oordenking van Ander ervarings is om die wêreld anders te sien, en in te sien dat die tradisionele verwoording van wat ervaring behels, nie net ongenoegsaam is nie, maar vals (kyk Foucault 1978:117). Hier waar hy die ervaring van die Ander gebruik om die tradisionele (moderne) onderskeid tussen waar en vals op die spits te dryf, bevind hy hom in die selfopgelegde niemandsland van die Ander, die 'gewelddadige buitekant', soos hy dit self genoem het (Foucault 1972: 224; 124). Kant se beroemde eerste van vier grondfilosofiese vrae, 'Wat kan ek weet?' word by Foucault: 'Wat is daar wat ek nie mag weet nie, maar moet weet?'. Foucault se geskiedenisse van die Ander wou aan hierdie vraag gestalte gee. 
Foucault se geskiedenisse, as kritiek van die rede, wentel rondom die konsepte van argeologie en genealogie. Liasgenoemde is onder meer 'n verwikkeling van eersgenoemde: argeologie wil poog om die waarheid-stigtende elemente in enige diskoers te identifiseer, veral waarom dit as waar (of redelik, of mooi of goed) sou geld. Waarom is dít redelik en dát onredelik? (On-redelik, dit wil sê, irrasioneel sowél as immoreel; Foucault is terloops baie sensitief vir die pejoriserende en emotiewe geladenheid van begrippe soos waar, redelik, mooi en goed.) Genealogie (bv Foucault 1977:145-146) wil verder gaan en die oorspronge van hierdie diskoerse identifiseer, hoé diskoerse dus gevorm word, maar veral, waarom diskoerse kom en gaan. In die proses rig Foucault hom op institusionele verskyningsvorme: waansin, byvoorbeeld, manifesteer in die gestig. Om waansin te peil, moet die gestig gepeil word. Om die aantreklike van die Ander in te sien, moet die onaantreklikheid aan die institusionele verdringing van die Ander blootgelê word: in die gestig, in die hospitaal, in die tronk. Dít is juis die aantreklike in Foucault se kritiek: dit is nie afstandelik en esoteries nie, maar militant hier en nou gerig op die institusionalisering van die Ander in 'n tronk, in 'n gestig, in 'n hospitaal en so meer. In hierdie institusies is sekere subjekte as krimineel, waansinning en siek geklassifiseer, en het só nie net objekte van kennis geword nie, maar ook objekte van oorheersing.

Madness and Civilization is nie net van belang omdat dit Foucault se eerste groot publikasie was nie, maar omdat die kontra-histories-historiserende trant en tematiese strekking van hierdie werk Foucault se opvolgende werk sou voed. Die werk beliggaam die kontra-historiese tema wat hierbo uiteengesit is, met spesifieke verwysing na die (psigiatriese) hantering van waansin in die moderne tyd. Foucault se werk hierna verleng bloot die historiografiese strategie waarmee hy hier besig is, terwyl hy telkens net die fokus verskuif na 'n volgende moderne institusie, byvoorbeeld na die tronk en na die liggaam. Reeds in die voorwoord van Madness and Civilization laat Foucault hom uit oor sy beskouing van die aard van die Verligting, naamlik dat die Verligting een omvattende magsdiskoers was (is). Dit is duidelik dat Foucault uiters skepties staan teenoor die Verligting wat die rede en waansin as teenoorstaandes geponeer het, juis vanuit die moderne rede se konsekwente neiging tot die verdringing en uitbanning van die dinge wat nie soos hy is nie.

Die Verligting bemoontlik 'n soort historiese taal wat by uitstek monologies van aard is: hy pretendeer om met gesag oor iets anders te praat terwyl hy eintlik besig is om oor homself te praat. So is die taal van die psigiatrie volgens Foucault by uitstek 'n moderne verskynsel, 'n monoloog van die rede oor wat nie redelik is nie (Foucault 1965:xiii). Dit het volgens Foucault tyd geword dat hierdie monoloog se onderdrukkende ritme verbreek word, en dat die historiese 'opstapeling van stiltes' aan die woord 
moet kom. Die stilte van die Ander word hier oopgeskryf en die, volgens hom, asimmetriese historiese verhoudings waarbinne (die diagnosering en tipering van) waansin as Ander tot stand gekom het, laag vir laag afgeskil. Dié afskil van historiese lae behels veral die omskrywing van en kommentaar op die wyse waarop (reduserende) kategorieë in moderniteit die mens terselfdertyd die subjek én die objek van kennis laat word het, 'n proses wat in wese gekonstitueer is deur die eerste van vele verdringingsaksies in moderniteit: die verdringing van alles wat nie redelik is of redelik verstaanbaar is nie.

Daarom begin die boek strategies met ' $\mathrm{n}$ sin wat minstens vreemd aandoen vir ' $\mathrm{n}$ boek waarvan die aanvanklike subtitel (A History of madness in the classical age) blyke van sober historiografiese aspirasies wil gee: 'Aan die einde van die Middeleeue het melaatsheid van die aardbol verwyn' (Foucault 1965:3). Op hierdie openingsin volg Foucault se omskrywing van wat die Verligting gemaak het met alles wat hy nie kon verklaar/hanteer/onderwerp nie: die 'vervloekte stede' wat (weg, buite) aangelê is om melaatses te huisves, word deur Foucault as 'n argetipe ingespan om die Verligting se verdringende hantering van alles wat gevaarlik/Anders gelyk het, van siek tot waansinnig, te beskryf. Foucault bou op hierdie kragtige metafoor vir Andersheid voort om 'n verband tussen waansin en die Ander te lê.

Dit is nie hier die plek om die teoretiese impakte van die werk op die psigiatrie breedvoerig te beskryf nie. Nogtans is dit nodig om op te merk dat dit na hierdie werk nie meer moontlik is om teoreties oor waansin as (byvoorbeeld biologiese) gegewe te reflekteer nie. Die teoretiese impak van die werk spreek eintlik vanself: dit bevraagteken die wetenskaplike status van die psigiatrie in die klassieke sowel as in die moderne tyd. Maar dit is nie waaroor Foucault dit werklik het nie: hy het dit oor die histories-etiese agtergronde, as mens dit so kan noem, van hierdie praktyke.

Daarom is die vraag: wat is Foucault se 'histories-etiese blik' op hierdie geinstitusionaliseerde verskynings van onderwerping en verdringing? Dit is 'n wesentlike vraag, want die antwoord daarop sê heelwat van Foucault se geskiedsbeskouing. Om hierdie vraag te beantwoord, kan gekyk word na Foucault se omskrywing van twee baanbreker psigiaters van die moderne tyd, naamlik Tuke (1732-1822) en Pinel (17451826).

Tuke en Pinel is tradisioneel as van die baanbrekers van die verligte en 'menslike' behandeling van geestesongesteldheid beskou. Tuke, in Engeland, het ' $n$ inrigting opgerig wat bekend was vir die feit dat daar geen fisiese beperking op die pasiënt soos tralies en stywebaadjies was nie. Pinel, in Frankryk, het pasiënte uit die tronkagtige omgewing by Bicêtre tydens die hoogbloei van die Franse Rewolusie bevry, met die merkwaardige stelling dat hulle toestand toe te skryf is aan die gebrek aan vryheid en 
vars lug (kyk Foucault 1965:242). In 'n radikale en karakteriserende herevaluering van Tuke en Pinel se hervormings gaan Foucault van die standpunt uit dat dit wat hier na vooruitgang lyk, wese:lik 'n (nuwere) vorm van sosiale onderwerping is. Danksy Tuke en Pinel se hervormings is waansin 'opgesluit in die morele wêreld' tot 'vandag toe' (Foucault 1965:269). Foucault benadruk Tuke se godsdienstige (Kwaker) agtergrond, om daarmee te kenne te gee dat werklike terreur juis plaasgevind het toe Tuke die 'vrye terreur van waansin' met 'n morele verantwoordelikheid vervang het, wat in elk geval 'n magshandeling is (Foucault 1965:247). Pinel se inrigting wat ook geen sigbare tekens van gevangehouding vertoon het nie, is nog meer bedenklik: volgens Foucault dui hierdie ontperking nie op 'n bevryde waansin nie, maar toon dit hoe lank waansin reeds onderwerp is deur 'n 'gedissiplineerde sisteem wat ontwerp is om die gewaarwording van skuld te bevorder' (Foucault 1965:252). Die pasiënt word behandel soos 'n stout kind wat dissipline nodig het. Die gevolg van hierdie Verligtingstrategie met betrekking tot die behandeling van die inmate, was soveel meer beskadigend omdat dit skuilgegaan het onder die historiese fasade en pretensie van menslikheid en vooruitgang, en hierdie fasade juis dít inhou en terughou wat nie gesien kan word nie. Pinel se pasiënt is ingedwing in 'n 'kalm wêreld van tradisionele waardes', terwyl daardie pasiënt gesmag het om uit te breek, terug na sy wêreld van 'woede en wreedheid'. Die stede vir melaatses, die Middeleeue se wrede 'kasteel van orde', is vervang met die onsigbare kerkers van die moderne bewussyn en gewete (Foucault 1965:11). Waar waansin in die Middeleeue buite (ook morele) oordeel gestaan het, het dit nou by uitstek die objek van (ook morele) oordeel geword (Foucault 1965:268). Pinel se 'bevryding' is net so paradoksaal as die Verligting se sogenaamde vooruitgangstrategieê: voor Pinel was die donker, die boeie, die spot en sarkasme vir die pasiënt in sy delirium die wesenselement van sy vryheid. In boeie kon die waansinnige nie losgemaak word van sy 'onmiddellike waarheid' nie. Maar toe die boeie eers opgeslaan is, is die waansinnige in ' $n$ wêreld van morele deugde ingebed wat deur herhaling en dissipline by hom/haar geinternaliseer is, en is hy/sy vasgevang in die 'wêreld van inhoudlose vryheid'. Sy/haar gevangenskap was nou meer werklik as toe hy in boeie was: ' $(\mathrm{Hy} / \mathrm{sy}$ is) ...'n gevangene van niemand behalwe homself/haarself nie'. Die samelewing word in die posisie geplaas om onskuldig te bly lyk, en die skuld is bloot na die waansinnige verplaas (Foucault 1965:260vv).

Hiermee sê Foucault nie alleen iets oor die Verligting se aanspraak op vooruitgang - maar dan deur fasade en onderwerping - nie, maar ook die Verligting se historiese hantering van skuld. Die individu wat waansinnige impulse beleef, sal gou ondervind dat die manier om dit uit te druk, self weer onderdrukkend is: die moderne sisteem skryf ook die uitdrukking van waansin voor (hoe 'n skisofreen byvoorbeeld behoort te 
reageer), en lê die skuld voor die morele deur van die individu wat die impuls beleef, dit uitleef en nie aan die voorskrifte/diagnoses voldoen nie. Slegs enkeles, soos Nietzsche se Zarathustra en Sade se Juliette, is volgens Foucault gelukkig genoeg om die 'massiewe morele gevangenskap'. van die Verligting, verbeeld deur Tuke en Pinel, te ontsnap (Foucault 1965:283): om te wees sonder om skuldig te wees.

Daar is egter ook meer hieraan: Foucault se dokumentering van die wyse waarop die mag wat 'waansin' genoem word, deur kulturele vorme en sisteme vir eie gewin gekaap word, impliseer dat Foucault daarvan oortuig is dat die moderne filosofie, vanaf Kant tot by Sartre, met uitsondering van Nietzsche, se indrukke van skuld en verantwoordelikheid radikaal misplaas is. 'Jy kan, want jy behoort', kan nie 'n universele kategorie wees nie: waansin as geldige ervaring bewys dit.

Dus: as 'n mens sou kon praat van die wesenskenmerk van Madness and Civilization, is dit die feit dat hier 'n skerp historiografiese kritiek van die Verligting en moderniteit se verdringingstrategieë en verborge antagonismes teen die Ander werksaam is. Die bepalende impak van die werk, wat eerder moraliteitskrities is as wat dit van werklike teoretiese belang vir die psigiatrie is, is gelee in die bepalende gedagte wat hierbo na vore getree het: waansin is nie immoreel nie, maar bloot Anders. Daar is iets Anders in die geskiedenis opgesluit as wat moderniteit ons wou laat verstaan. Die man wat 'mal' genoem word, is onskuldig: dit is die moderne samelewing wat skuldig is.

Foucault is nie besig om net die rolle om te ruil en basies in die dieselfde logika te bly vassteek nie. Want Madness and Civilization beskryf nie net die toenemend rasionelc wyse waarop waansin beskou is en aangespreek is nie, maar ook hoe die moderne konseptualisering van waansin gefunksioneer het om sogenaamde normaliteit te legitimeer en die ervaring aan madness te ontkragtig. Die Verligting se beloftes van vryheid, vooruitgang en geregtigheid is maar net die maskerade waarmee die beskadigingsmeganismes van oorheersing, onderdrukking en dissiplinering hulleself in die moderniteit handhaaf. Die Verligting werk met 'n skynbelofte van 'n skynvooruitgang. Die Verligtingsgeskiedenis is skyngeskiedenis.

Foucault se werk is spesifiek toegespits op die vorme wat hierdie verdringingsmoontlikhede en verdringingsmeganismes histories en institusioneel bemoontlik en afgedwing het. Om hierdie wending in Foucault se werk te verstaan, is dit weer nodig om Foucault se beskouing van die werking van mag in die moderne tyd onder die loep te neem - daar is reeds aangedui dat Foucault eg-Nietzscheaans heelwat konstruktiwiteit in mag eien. Foucault evalueer mag positief: mag is anoniem, produktief en onidentifiseerbaar - oral. Foucault hanteer mag spesifiek as 'n historiese verskynsel. Dit is juis omdat mag histories-bepaald is, dat Foucault betoog dat mag produseer, en nie noodwendig uitsluit, onderdruk, abstraheer en sensureer nie. Mag is produserend: dit produseer domeine van die objek en rituele van waarheid. 
Volgens Foucault kan mag egter nie die besitting van 'n bepáalde groep of individu wees nie: mag is anoniem. Mag is spesifiek so anoniem, omdat die moderne vorme van administrasie en burokratisering geweldig anoniem is. Daarom gee Foucault ook nie werklik aandag aan die Marxistiese begrip van klassedominansie in sy werk nie, en bly mag vir hom 'n 'masjien waarin almal opgeneem word, diegene wat die mag uitoefen sowel as diegene oor wie dit uitgeoefen word' (Foucault 1980:156). Foucault is dus agterdogtig oor die gevolge van die inperkinge op die historiese werklikheid, en die skadelike gevolge van hierdie inperkinge, wat deur instrumentele redelikheid onderskraag is. Die gewaarwording van mag, oorheersing, destruksie en uiteindelik dekonstruksie is eie aan sy werk. Daar is iets van 'n disintegrasie van dinge in sy werk af te lees. Hy rig hom wesenlik teen die dwangmatige inperkinge van die paradigma van die subjekfilosofie.

Die vraag is nou of Foucault in hierdie gerigtheid op die onmiddellike teenswoordige aard van oorheersing règ laat geskied aan die geskiedenis. Foucault, en dit is belangrik om dit in te sien, het dit juis nié oor die vergange geskiedenis nie. Foucault het.dit oor die huidige geskiedenis. Sy 'historiese projekte' is maar bloot die media wat hy inspan om die huidige geskiedenis te red van verdere verenging en die selektiewe (en arbitrêre) verdaging van sekere momente uit die huidige geskiedenis. Daarom is begrippe soos 'argeologie', 'genealogie' en 'geskiedskrywing' by Foucault maar net maskers van 'n baie groter projek, naamlik 'n voldoende kritiek van 'n verengde en verengende rede. Foucault wil die magspatrone wat tot hierdie verenging gelei het, blootle. 'Die geskiedenis is bloot die medium waarmee hy werk. Hierdie medium is by uitstek aan Nietzsche ontleen, in die resepsie en oorname van die gedagte van die universaliteit en kragtigheid van mag, spesifiek mag as diskoerskonstituerend (kyk bv Foucault 1977:112). Die dringkrag van Foucault se 'historiese analises', of alternatiewe geskiedenisse, is dus dat die Ander oopgeskryf moet word.

In hierdie oopskrywing is Foucault besonder geinteresseerd in die ontwikkeling vanaf die positiewe Sokratiese opdrag 'ken jouself!' na die negatiewe Christelike opdrag 'verraai jouself!', meer spesifiek, 'verwerp jou liggaam!'. Foucault is daarom geïnteresseerd in die gedagte van Selfopoffering, van martelaarskap, die negering van die Self (Foucault 1977:29) in die Christelike tradisie. Die gevalle, sondige liggaam moet volgens hom gerehabiliteer word: dit is die siel wat die liggaam pynig, en dit is die liggaam wat van die siel bevry moet word, en nie andersom nie.

Hier sluit Foucault ooglopend aan by talle passasies in Nietzsche se Zarathustra, waar die karakter Zarathustra dieselfde ingewing het, asook met die gedeelte in Nietzsche se studie oor Schopenhauer, waar Nietzsche eksplisiet die belangrike vraag vra: hoe het ek geword wat ek is, en waarom ly ek, my liggaam, onder wat ek is? 
(kyk Arrowsmith 1990 [vert]: 191 [par 4]). Daarom was Foucault ook gefassineerd met die proses wat 'n mens kan noem 'n transformasie van die Ander en om iets Anders te word (kyk bv Foucault 1988a:9). Foucault se geskiedenis is eerder 'n geskiedenis van waansin as van kwansuise betekenis, eerder byvoorbeeld die geskiedenis van die gevangene as beheersde Ander as 'n geskiedenis van die gevangenis.

Dit is ook 'n voorbeeld van Foucault se eksponering van die postmodèrne krisisbewussyn of kultuurpessimisme, wat via Nietzsche na hom toe aankom, en wat in sy werk letterlik ongekende afmetings aanneem. In Foucault se Order of things verdwyn die subjek totaal uit die prentjie, en word die wêreld as blót taal, blót diskoers verklaar, subjekloos en objekloos. Die diskoers bly anoniem en gesigloos oor. Met diskoers wat as alleenstaande oorbly, begin daar nou 'n fassinerende en kritiese strekking by Foucault ' $n$ loop neem: die diskoers het ook met die subjek weggedoen. Die diskoers ontneem dinge hul representasievorme. Foucault is so 'n radikale nominalis in sy geskiedenisse dat die individu dus ook verdwyn. Hy fokus op anonieme institusies wat volgens hom anonimiteit afdwing. So kry ' $n$ mens by Foucault moeilik die portret van ' $n$ gevangene, ' $n$ mens. Foucault se geskiedenisse is eerder 'n geskiedenis van die moderne rede wat gereken het dat 'n sinnige onderskeid tussen redelik en kranksinnig gedoen kan word. Nietzscheaans beskou, kom dit neer op 'geen feite, slegs interpretasies'. Die interpretandum is altyd rééds interpretans.

'n Mens lees dus nie geskiedenis nie, maar is dit. Die geskiedenis kan nie as ding interpreteer word nie, maar slegs as rééds interpretasie. Die geskiedenis, soos kuns, kan nie dieperliggend geïnterpreteer word nie, geen intensie om te ontdek kan slaag nie. Die ding is reeds diskoers. Hierdie aksentuering van diskoers vind in sy Archaeology of knowledge (1972) neerslag, in Foucault se (telkens-hernieude) aanval op die Cartesianisme, met ander woorde, die totale geskiedenis van subjektivistiese klemtone wat die moderne wetenskap en tegnologie voorafgegaan het. Hy parodieer Descartes selfs deur met 'n metodologiese twyfel te begin, maar hy hou nie op twyfel nie. Sy twyfel is ironies en uiteindelik volslae onmetodies. Dit is 'n dionisiese stuk onwetenskaplikheid wat wetenskap wil vernietig, maar 'n diskoers wat genealogie bemoontlik. Dié genealogie vergestalt die radikaliteit van die diskoers, die radikaliteit binne teoretiese raamwerk: genealogie analiseer en beskryf nie net die Ander werklikheid nie, maar wil dit oorstyg, diskoers as historiserende praxis wees.

By Foucault is daar egter op die oog af ' $n$ ambivalensie tussen burokratiese mag en produktiewe (eie) mag werksaam. Met sy veralgemening van mag, as sou dit oral en onontkombaar wees, bring Foucault, met of sonder opset, die gedagte van die ontmaskering van mag na vore. Moderne sisteme, soos dié van Marx, se aanspraak op die 
ontmaskering van mag en die blootlegging van die uitwerking van mag, in byvoorbeeld onderdrukkende ekonomiese sisteme, sou volgens Foucault nou tot 'n einde kom: Foucault wil by ons tuisbring dat ons nie van magsregimes kan ontsnap nie, maar (skynbaar) slegs van een regime van mag na 'n volgende kan beweeg.

Foucault sit juis hier met dieselfde probleem as waarmee talle postmoderne denkers (veral ook Levinas) te doen het: sy kritiek is noodwendig selfverwysend, en dit tref hom ewe hard. Die kritiese vraag is dus wat die status van Foucault se eie magsteorie is. In watter magsdiskoers is Foucault se teorie dan ingebed? (kyk ook Derrida 1978:34 se kritiek oor Foucault se eie [enigsins willekeurige] omgang met die 'taal van die rede' en 'taal van waansin'.) Foucault het wel hierop geantwoord (alhoewel onbevredigend?): Hy hou naamlik vol dat hy nie met 'n 'teorie' van mag of met 'n waarheidsteorie besig is nie, maar met 'n 'teenswoordige geskiedenis' (kyk Foucault 1980:133).

Sy genealogie is volgens Foucault 'spesifiek' en nie 'universeel' nie: die spesifieke intellektueel - in hierdie geval Foucault - is nie self die stem van die rede of die stem van waarheid nie, maar 'veg om rede en waarheid van mekaar los te maak' binne 'n spesifieke struggle. Kritiek is die instrument van struggle waarmee die filosoof, al is dit net vir die oomblik geldig, die magsverhouding in die huidige waarheidsregime wil verander (Foucault 1980:134). Dit lyk nogtans nie of Foucault uan die feitelike implikasie van sy teorie ontkom nie, naamlik dat hyself met 'n magsdiskoers besig is wat ewe beskadigend kan wees as die moderne diskoers waarteen hy dit het.

Nogtans staan dit vir eers vas dat ' $n$ /die geskiedenis na Foucault nie onaangeraak kan bly nie: Histories (untouched) teach us nothing. Dit geld ook vir sy geskiedenisse.

\section{Literatuurverwysings}

Arrowsmith, W 1990. Schopenhauer as Educator. 'n Kommentariëring en vertaling van Nietzsche se teks. New Haven: Delta.

Deleuze, G 1984. 'Nomad thought', in Allison, D (ed), The new Nietzsche, 141-149. Cambridge, Mass: MIT.

1986. Foucault. Minneapolis: MUV.

Derrida, J 1978. Writing and difference. Londen: Routledge.

Foucault, M 1965. Madness and civilization: A history of insanity in the age of reason. New York: Random House.

- 1972. The archaeology of knowledge. Londen: Tavistock. 1977. Language, counter-memory, practice. Oxford: Blackwell.

1978. History of sexuality, Vol 1. New York: Random House.

1980. Power/knowledge: Selected interviews. New York: Random House. 
Foucault, M 1985. The use of pleasure. New York: Random House. 1988a. 'Truth, Power, Self', in Martin, L H, Gutman, H \& Hutton, P H (eds), Technologies of the Self. Cambridge, Mass: Amherst.

1988b. Politics, Philosophy, Culture. New York: Random House.

1991. Remarks on Marx. New York: Random House.

Levinas, E 1969. Totality and infinity. Pittsburgh: Duquesne University Press.

Lyotard, J-F 1984. The postmodern condition. Oxford: Manchester University Press.

Taylor, C 1989. Sources of the Self: The making of the modern identity. Cambridge: Cambridge University Press. 